\title{
Tidal energy from the Severn estuary, UK
}

Chris Binnie MA, DIC, HonDEng, FREng, FICE, FCIWEM

Independent Consultant, Minehead, UK; Visiting Professor, Exeter

University Water Centre, Exeter, UK (previously Chairman of the

Engineering and Technical Expert Panel for DECC for the Severn Tidal

Power Studies; Director Atkins plc; Management Board of the Severn Tidal

Power Group studies; Past President Chartered Institution of Water and

Environmental Management)

The Severn estuary in Britain has the second highest tidal range in the world. However, the estuary and much of the adjoining Bristol Channel are too shallow for current commercial tidal stream arrays of the horizontal-axis type. The most successful tidal range scheme is the La Rance scheme in Brittany, France, which has operated for 45 years and produces the cheapest electricity in Europe. Tidal range schemes in the Severn estuary have been studied several times. The Department of Energy and Climate Change study in 2008-2010 showed a Cardiff/Weston ebb-only barrage (15.6 TWh/year) and the Bridgwater Bay ebb/flood lagoon (6.2 TWh/year) to be feasible, but with appreciable environmental issues. More detailed environmental and planning studies would be needed to demonstrate compliance with the EU Habitats Directive. Several smaller lagoon schemes have also been proposed and the Swansea Bay scheme is $\mathbf{0 . 4} \mathrm{TWh} /$ year currently seeking planning permission. Thus, the total energy output from tidal range in the Severn could be about $25 \mathrm{TWh} / y e a r$, about $7 \%$ of the UK energy needs. The energy available would be predictable and, if aligned with tidal lagoons on the North Wales coast and elsewhere, continuous, although varying with the spring and neap tidal cycles.

\section{Introduction}

Britain's Bristol Channel and adjoining Severn estuary together form a long and funnel-shaped area of sea, causing the tidal range to increase from a maximum of $7 \mathrm{~m}$ at the outer reaches to about $14 \mathrm{~m}$ at Avonmouth. This is the second highest tidal range in the world. There is, thus, considerable energy locked up in the tidal excursion. Tidal energy can either be harnessed by damming a portion of the estuary and using the subsequent head differential to generate power from the tidal range, or else having turbines underwater in the sea, similar to wind turbines, developing energy from the flow of the tidal currents. This paper looks at the various ways the tidal energy from the Severn estuary/Bristol Channel could be harnessed. This paper thus provides an overview of the Severn estuary as a tidal energy source, including the potential schemes, their issues and their benefits.

\section{Typical tidal range scheme}

\subsection{Traditional ebb generation scheme}

The traditional tidal range scheme has a barrage across the estuary. Within this, there are large sluices that let the incoming tide flow into the upstream basin and then, as soon as the outside level and basin water level are similar, they are shut. The typical water levels of the sea and the basin are shown in Figure 1. The barrage line would also include turbines in large caissons. As soon as sufficient head differential had built up between the basin water level and the dropping sea level outside during the ebb tide, the turbines would be opened for operation and would generate electricity. An embankment would connect the ends of the sluices and turbines to the shore, thus completing the barrage.

Such a scheme is called ebb generation and this maximises the power output. However, the in-basin high water level would be reduced by typically $1 \mathrm{~m}$ and, depending on the number of turbines, the basin low water level would be considerably raised and not reduce much below the mean tide level.

\subsection{Ebb/flood generation scheme}

It is possible to design the turbines to generate on both the ebb and flood tide (generally referred to as ebb/flood or bi-directional generation). The water levels of a typical ebb/flood generation scheme are shown in Figure 2. Such turbines have to compromise on the hydraulic shape to work in both directions; thus, the turbines' overall hydraulic efficiency would be less. Such a scheme also results in further lowering of the peak basin water level (typically by about $1 \mathrm{~m}$ ), although the basin 


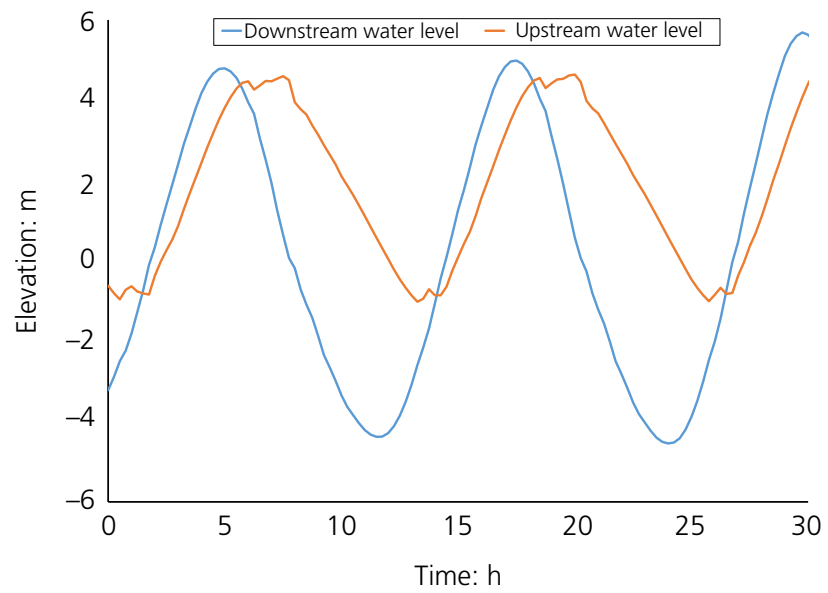

Figure 1. Ebb generation tidal range level diagram (reproduced with permission of Professor Roger Falconer, Cardiff University)

low water level would be significantly less raised. The consequence is that the tidal range profile of the impoundment basin would be symmetrically suppressed and less distorted than in the case of ebb-only generation.

\subsection{Pumping}

One refinement is, at the end of the generation cycle when the head difference is too low to generate, first to let the water flow through the turbines and any of the open sluice gates, and then when the water level difference is low, to use the turbines as pumps. While this does mean energy use, it is when the water difference is low; the pumped water could then be used to

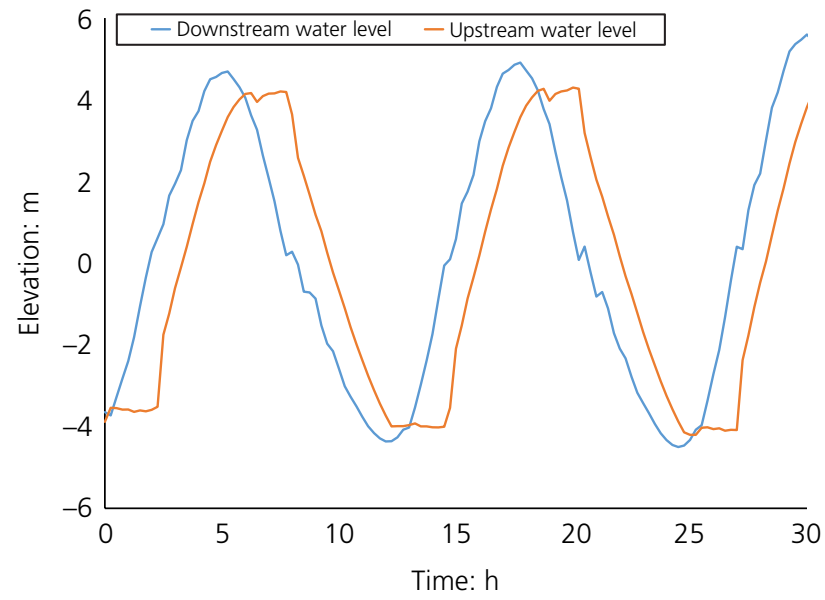

Figure 2. Ebb/flood generation tidal level diagram (reproduced with permission of Professor Roger Falconer, Cardiff University) generate power when the head difference is much greater. Thus, there could be some energy gain. A benefit would be that the basin water levels would be closer to the current range, hence reducing the loss of intertidal habitat and the need for compensation habitat. This could be particularly effective for lagoons and for low basin water level for the barrage. Consideration would also need to be taken of the time of day, and the costs and value of the energy. Pumping can be useful, particularly at neap tides, and when the value of energy changes such that pumping is done when energy is cheap and generation when energy is more valuable.

\subsection{Power generation}

One downside of tidal power is that the energy produced varies between spring tide and neap tide, such that the latter is less than half the former. However, in contrast to most renewable forms of energy (in particular, wind and wave power), one major advantage of tidal power is that its potential output is predictable many years in advance.

An ebb/flood generation scheme would have a lower peak power output than an ebb-only generation scheme, making it easier for the national grid to cope with the power generated. Due to the four pulses of energy a day compared with two for an ebb-only generation scheme, the energy generated by an ebb/flood generation scheme is likely to be similar to that of an ebb-only generation scheme (Figure 3 ). The electricity grid would be better able to absorb the lower peak power. The time of power generation would increase from about an average of $11 \mathrm{~h} / \mathrm{d}$ for ebb only to about $15 \mathrm{~h} / \mathrm{d}$ for ebb/flood generation with a maximum gap of about $2 \frac{1}{2} \mathrm{~h}$. Thus, electricity storage (e.g. pumped storage such as the $1650 \mathrm{MW}$ (mega watt, 10 to the sixth power) Dinorwig Power Station) and demand management, such as that achieved by 'smart' appliances/metering and electric vehicle batteries, would be able to cope more easily with the power fluctuations from an ebb-flood tidal scheme.

Furthermore, tidal lagoons along the North Wales or North West of England coast would have a tidal cycle of about $4 \mathrm{~h}$ different from the Severn and would, therefore, provide power during the period when the Severn estuary could not.

\section{Existing tidal power schemes}

\subsection{La Rance tidal range scheme}

In the 1966, EdF completed the 240 MW La Rance tidal power scheme (Figure 4). This is on a long narrow estuary on the North Brittany coast with a maximum tidal range of about $13.5 \mathrm{~m}$. This has 24 horizontal bulb turbines $5.35 \mathrm{~m}$ dia. and six sluice gates; now, after early trialling of a variety of generation combinations, including ebb/flood, it operates in the ebb generation mode and, occasionally, with pumped augmentation of the head at the end of each sluice-filling phase. Thus, there 

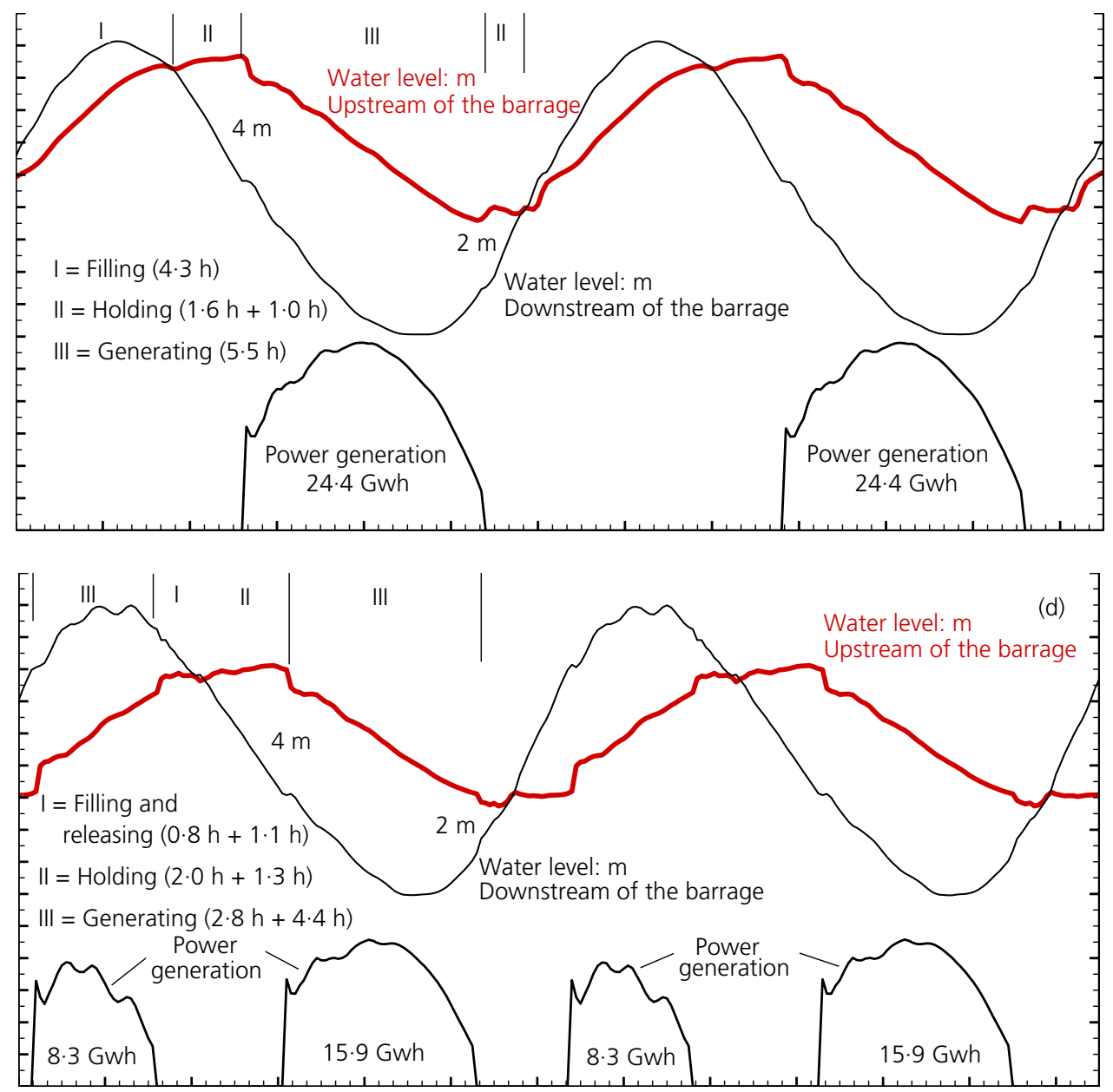

Figure 3. Ebb only and two-way generation power pulses (reproduced with permission of Professor Roger Falconer, Cardiff University)

has been good experience with the design and operation of this tidal range scheme. This has shown that after some 45 years of operation, the civil engineering works are in good state and so far only the electrical equipment has had to be changed. It generates $0.54 \mathrm{TWh} /$ year (tera watt hours per year, 10 to the 12th power) (Perier, 2013) at a cost of energy of around $€ 20 / \mathrm{MWh}$, the cheapest electricity available in the market.

The La Rance scheme was constructed in a watertight cofferdam right across the narrow estuary. Thus, no migratory species or resident/transient species could pass during the 3-year construction period. Regrettably, there was no baseline environmental study conducted prior to construction. Further, the salinity of the basin reduced considerably during construction; thus, nearly all marine species were wiped out. However, within 5 years, the typical benthic and midwater communities had re-established. The reason this happened so quickly was due to the high level of daily water exchange between the basin and coastal waters, which allowed larvae, juveniles and adults to enter the basin (Desroy, 2013).

It is reported that fish, crustaceans and molluscs pass through the power station without difficulty (Kirby and Retiere, 2009). There are now 70 species of invertebrates and fish in the basin (Kirby and Retiere, 2009). Cuttlefish reproduce in the basin and then head towards the sea at the end of summer, returning to spawn next spring. Shad and salmon spawning grounds upstream were wiped out in the nineteenth century by the construction of upstream weirs. However, the La Rance basin has now become a designated Natura 2000 site, including breeding shad. IFREMER compared the La Rance tidal power basin with the Trieux estuary about $100 \mathrm{~km}$ west (considered 


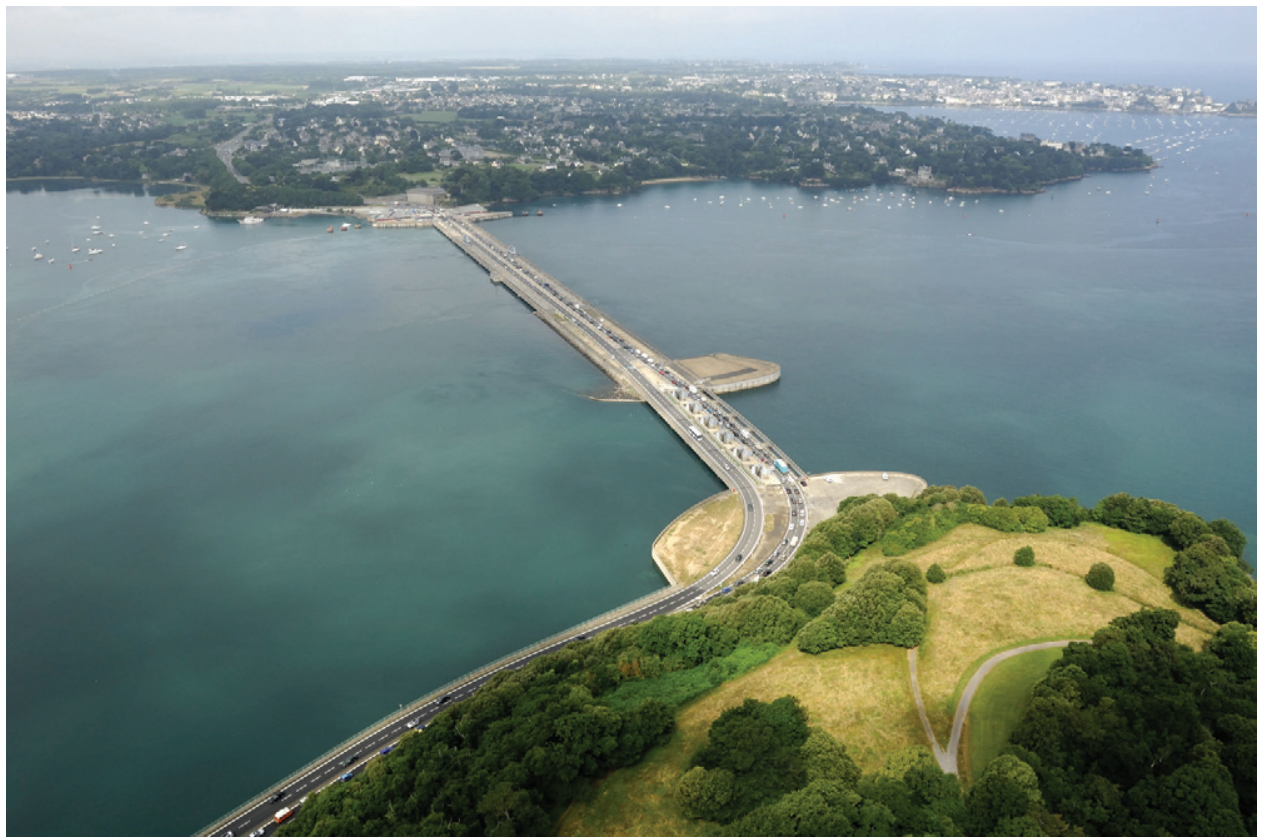

Figure 4. Aerial view of La Rance tidal range power station during flood sluicing (reproduced by permission of EdF, France)

homologous), and found abundance and diversity had similar values (Desroy, 2013).

Once the barrage became functional, the deposited sediments in the main channels were resuspended and the fine sediments were redeposited in the side channels and upstream (Desroy, 2013). The result is that the carrying capacity of the inter-tidal area has increased, compensating for the 33\% of inter-tidal area lost. La Rance is now more important than before in respect of its waterbird numbers (Kirby and Retiere, 2009).

The socio-economic benefits of the scheme include greatly increased sailing and water-based recreation with 20000 boats per year passing through the lock, a road over the barrage allowing shortened journey times along the coast and much tourist interest in the scheme, with 70000 visitors per year (Perier, 2013).

\subsection{Annapolis Royal}

The Annapolis Royal scheme is a very small-scale tidal scheme on the Bay of Fundy, the area with the highest tidal range in the world. This has a single prototype $7.6 \mathrm{~m}$ dia. $20 \mathrm{MW}$ Straflow turbine installed in an existing embankment constructed in the 1960s and operating in ebb generation mode. It was commissioned in 1984 . This had been planned as the prototype for a $1400 \mathrm{MW}$ scheme. However, it was found that the main scheme would raise the sea level on the coast of Maine in the USA by $30 \mathrm{~mm}$ or $130 \mathrm{~mm}$, depending on the scheme involved (Baker, 1992). Many coastal installations along the US coast in the Gulf of Maine were built long ago; since then, the Maine coast has sunk and the mean sea level has increased. As a result, safety factors have been eroded and the US Army Corps of Engineers then advised that the damage threshold was at spring high tide level. Further, the USA authorities disputed the model predictions (Baker, 1992). Thus, the full-scale scheme was abandoned and the Canadian government switched to conventional inland hydropower for which it had many economic sites.

\subsection{Sihwa Lake Tidal Power Station, South Korea}

In 2011, the Korean Water Resource Corporation commissioned the $254 \mathrm{MW}$ Sihwa tidal power scheme. The tidal barrage makes use of a sea wall constructed in 1994 for flood mitigation purposes. After the sea wall was built, pollution built up in the newly created Sihwa Lake making its water useless for agriculture. In 2004, sea water was reintroduced in the hope of flushing out contamination and it was planned that the tidal power scheme flows would be complementary.

The scheme uses ten $7 \cdot 2 \mathrm{~m}$ dia. $25 \cdot 4 \mathrm{MW}$ bulb turbines operating in flood generation mode only. This relatively inefficient mode was chosen to balance a complex mix of existing 
land use, water use, conservation, environmental and power generation considerations. The mean operating tidal range is $5.6 \mathrm{~m}$ with a spring tidal range of $7.8 \mathrm{~m}$. The cost of the power station was around $\$ 250$ million.

South Korea had intended to construct several other tidal power schemes, including the $1320 \mathrm{MW}$ Incheon Bay plant. However, these would threaten ecologically important wetlands, including the $24 \mathrm{~km}^{2}$ Jangbongdo Wetland Preservation Area. These wetlands host tens of thousands of migrating birds that travel along the East Asian-Australian Flyway. Korea's Ministry of Environment pointed out considerable flaws in the preliminary environmental impact assessment (EIA) for the Incheon Bay Scheme. The Ministry of Land Transport and Maritime Affairs has had to defer their plans for the Ganghwa and Incheon Bay tidal power projects until more studies are carried out (Ko and Schubert, 2011).

\section{Severn tidal range barrage studies}

\subsection{Department of Energy studies, 1970s}

How to obtain tidal energy from the Severn was studied by the Severn Barrage Committee on behalf of the Department of Energy in the late 1970s. It published Energy Paper Number 46 in 1981 (DoE, 1981). This looked at an outer barrage on the Minehead/Aberthaw line, an inner barrage on the Cardiff/ Weston line and a staged scheme. One conclusion was that two basin schemes designed to spread generation outputs over a longer period were not economical to construct and should, therefore, not be studied further. The inner barrage, with an installed capacity of some $7200 \mathrm{MW}$ of bulb turbines operating in ebb generation mode, while having less energy than the outer line, was somewhat lower in energy cost. The report concluded that the pre-feasibility study had established that it is technically possible to construct a tidal barrage across the Severn estuary to generate electricity.

\subsection{Severn Tidal Power Group (STPG) studies}

The STPG consortium was formed by six contractor and equipment suppliers in 1983. The studied tidal range power schemes are at the English Stones (Shoots) close to the Second Severn Crossing and the Cardiff-Weston line. Both were conventional ebb generation schemes using bulb turbines. The cross-section of a turbine caisson is shown in Figure 5. The study concluded (STPG, 1986) that the English Stones scheme was less economical and also was likely to suffer from serious sedimentation issues. The large amounts of sediment in the water downstream would be carried upstream on the flood tide and then, during the longer high water stand, a part would

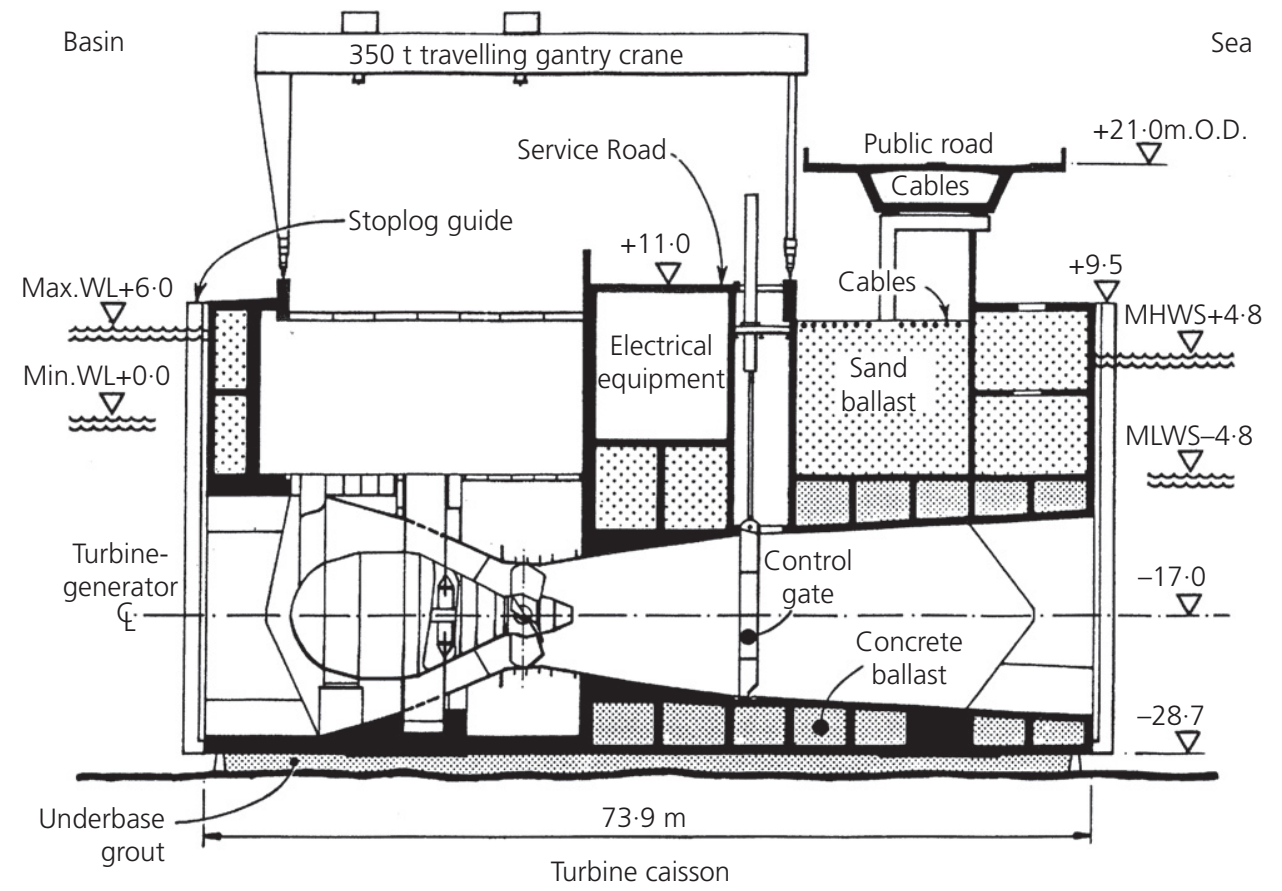

Figure 5. Cross-section of an ebb generation power station (from Energy Paper 57, The Severn Barrage Project 1989, figure 2·4, reproduced with permission of TSO) 
settle down leading to upstream siltation. The Cardiff-Weston scheme was favoured.

STPG was then contracted to the Department of Energy. It carried out site investigation of the Cardiff-Weston barrage line with geophysics and boreholes. It also prepared designs and carried out modelling of the construction movement of the caissons. It concluded (HMSO, 1989) that such a Cardiff/ Weston tidal power scheme with an installed capacity of $8640 \mathrm{MW}$ was feasible, but with the then prevailing price of energy, the rates of return available were considered insufficient to attract private investment for bearing the full risk of the project. Thus, at that time, the scheme would need public sector financial support that was not forthcoming.

\subsection{Department of Energy and Climate Change (DECC) studies, 2008-2010}

In 2008, DECC embarked on a major study of the energy that could be obtained from the Severn estuary. It called for ideas from the public as well as to identify a number of schemes itself. It appointed consultants Parsons Brinckerhoff (PB) in association with Black and Veatch, previously known as Binnie and Partners. This study included the most westerly barrage line, Minehead to Aberthaw, several inner barrage lines, several bunded lagoon schemes as well as several innovative ideas. At the end of phase one of this study, five schemes were selected for further study along with three innovative ideas (PB, 2008).

Although the Minehead/Aberthaw line produced the maximum energy at $25.3 \mathrm{TWh} /$ year, with a levelised cost of $8 \%$ more than the main scheme, the problems of grid acceptability of the large $14.8 \mathrm{GW}$ intermittent power output, particularly during the low-demand period at night, increased the environmental impact and the large compensation area required, meaning it was deemed impossible to be carried forward. However, if the country were to change from oil-based transport propulsion to another form, such as hydrogen, that required long-term cheap electricity to generate it and the scheme was to be operated in ebb/flood generation mode, then this scheme should be reconsidered.

The five schemes carried forward to phase 2 of the study included barrages on the Cardiff/Weston, English Stones and Beachley lines, and bunded lagoons at Bridgwater Bay and the Welsh Grounds (see Figure 6 for the locations of these schemes). All other bunded lagoons were rejected as uneconomic.

During phase 2 studies (PB, 2010), the Beachley barrage, B5, and the Welsh Grounds bunded lagoon scheme, L2, were found to be uneconomic. In general, lagoon schemes with their much longer retaining walls incur higher costs than barrages, but have much less impact on migratory fish and port navigation.
The Bridgwater Bay lagoon was changed to ebb/flood generation and its installed capacity increased considerably to minimise the area of inter-tidal mudflat lost.

Although the Shoots (English Stones) scheme, B4, was not more economical than the main scheme, its development would mean much less of the available tidal energy would be harnessed and it would have had a sedimentation risk.

Lagoon schemes outside the main barrage line would have limited impact on the energy and viability of other lagoons or the main B3 barrage; any tidal range lagoon within the barrage line would entail that the main barrage scheme would have appreciably reduced energy output and therefore would be unlikely to be developed for many decades to come. Thus, the Shoots scheme B4, the Welsh grounds lagoon L2 or similar lagoons would effectively sterilise much of the total energy potential of the Severn estuary.

The main Cardiff-Weston scheme was found to have the best value for money. Its carbon payback period would be only $2^{1 / 2}$ years. However, it would have a number of environmental and planning impacts. These are considered in more detail below.

The government concluded (DECC, 2010a) that it did not see a strategic case to bring forward a Severn tidal power scheme in the immediate term. The key conclusions of the feasibility study were: the scheme is unlikely to attract private investment in the prevailing circumstances and would require the public sector to bear much of the cost and risk.

The study also reported on the three embryonic technologies that had been funded. These were a tidal fence, a tidal bar and a spectral energy convertor. On the tidal fence, DECC (2010a) did not believe that a tidal stream scheme in this format would be feasible or would represent a strategically significant use of the estuary's resources. It would generate only $0.88 \mathrm{TWh} /$ year and either preclude development of the barrage or else have to be written off should government later decide that a barrage should be built to maximise energy capture from the Severn estuary resource.

For the spectral marine energy converter, there were wide ranges in cost and output, and no clear conclusion could be drawn except that the scheme was a long way from technical maturity and had much higher risks than the other schemes the feasibility study had considered.

The tidal bar used the development by Rolls Royce of new turbines designed specifically to operate in ebb and flood modes, with very low heads of water (Atkins and Rolls Royce, 2010). The slow-moving contra-rotating turbine concept has 


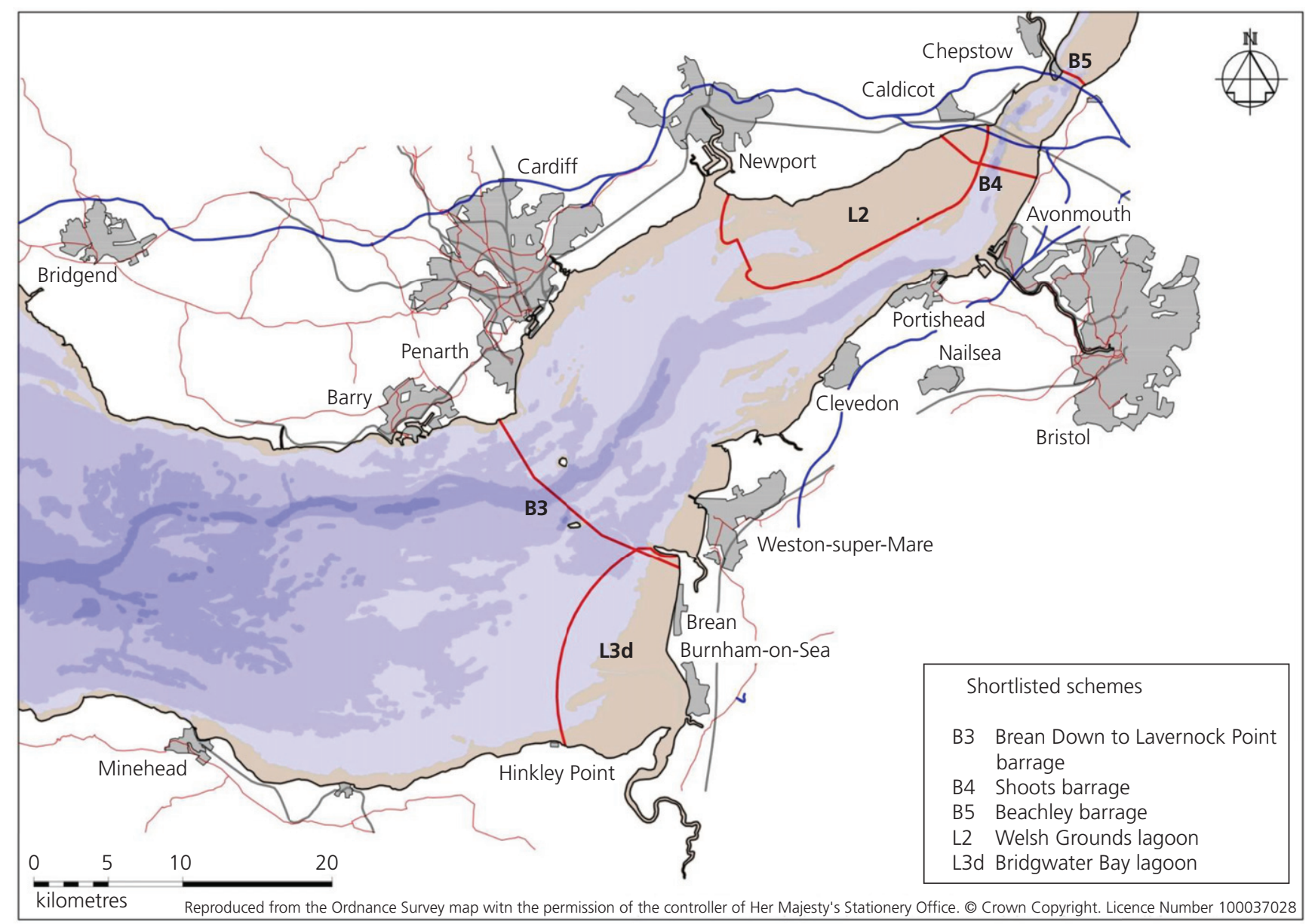

Figure 6. Plan of the five schemes from DECC/PB reports

(reproduced with permission of Parsons Brinckerhoff and DECC)

been developed with fish passage in mind. However, the effectiveness of this turbine configuration would need to be substantiated by further development and prototype testing (DECC, 2010a).

\subsection{Hafren Power (HP) ebb/flood generation proposal}

In 2012, Corlan Hafren and then HP proposed a scheme utilising the Rolls Royce very-low-head (VLH) turbine. This was primarily to overcome the problems of bulb turbines causing mortality in fish passing through the turbines. It was also clear that to minimise environmental impact the basin water levels should, as much as possible, follow the natural tidal variation and that would involve ebb/flood generation. Due to the lower power output of the low-head turbines, more turbines would be required; thus, the barrage line needed to be longer and thus had to be realigned to the southwest of both Flat Holm and Steep Holm, with a landfall near Brean (HP, 2013).
The proposed scheme would have 1026 low-head turbines, similar to the Atkins/Rolls contra-rotating turbines, to produce about $6500 \mathrm{MW}$ and an anticipated annual energy output of up to $16.5 \mathrm{TWH} / \mathrm{year}$. The energy output and capital cost would be similar to the DECC ebb-only scheme.

The Rolls Royce contra-rotating turbines are a novel concept. To reduce impact on fish, the blade tip velocity would be reduced to about $9 \mathrm{~m} / \mathrm{s}$. While early development work had been carried out such a turbine would need to be fully developed, and a prototype built and tested, including fish trials. Developing a new turbine is expensive, but the scale of the barrage scheme would be able to afford such development costs.

The HP scheme was considered by the Energy and Climate Change Select Committee who concluded 'Hafren Power has yet to provide robust and independently verified evidence of 
the economic, environmental and technological viability of the project. Nevertheless, the government should remain open to considering any marine project in the Severn which is able to comply with the requirements of the relevant EU and UK legislation including a potential barrage scheme' (ECCSC, 2013). HP has failed to raise the money to carry out the relevant studies.

\subsection{Swansea Bay lagoon}

For several years there have been proposals to develop tidal power in Swansea Bay by using a lagoon. The latest tidal power unit, by Tidal Lagoon (Swansea Bay) Ltd., would be attached to the shore and cover an area of about $11.5 \mathrm{~km}^{2}$ between the River Neath on the east and the River Tawe on the west (TLL, 2013) (Figure 7). The installed capacity is quoted as 16 number $15 \mathrm{MW}$ turbines totalling $240 \mathrm{MW}$ and the reported energy output to be $0.4 \mathrm{TWh} /$ year. The bulb turbines would operate in ebb/flood generation mode for about $14 \mathrm{~h} / \mathrm{d}$. The capital cost has been estimated as $£ 850$ million. An EIA and development consent application has been considered by the Planning Directorate and is currently being considered by the relevant ministers. It seems likely that Swansea
Bay lagoon will become the largest tidal range scheme to be built in the UK this decade, thus providing good experience of such schemes and encouragement for other tidal range schemes. This would meet the ECCSC 'recommendation to first develop a smaller-scale tidal project, in order to build a stronger evidence base for assessing impacts, risks and costs before proceeding with any larger-scale scheme' (ECCSC, 2013). Thus, no larger scheme should be implemented until the Swansea Bay scheme has provided construction and operational experience.

\subsection{Other lagoons}

Tidal Lagoon Ltd. (TLL), a private company, has recently announced plans to promote a Cardiff lagoon and a Newport lagoon in locations similar to those studied by DECC. These would be ebb/flood generation with an installed power of up to $2800 \mathrm{MW}$ at Cardiff. Of concern is that these would take up energy storage volume within the main barrage line. Thus, if these were to be built, then it is unlikely that the barrage would be economical, and vice versa. Thus, government will need to decide whether to safeguard the barrage scheme and thus not have significant lagoon storage upstream of the barrage or to

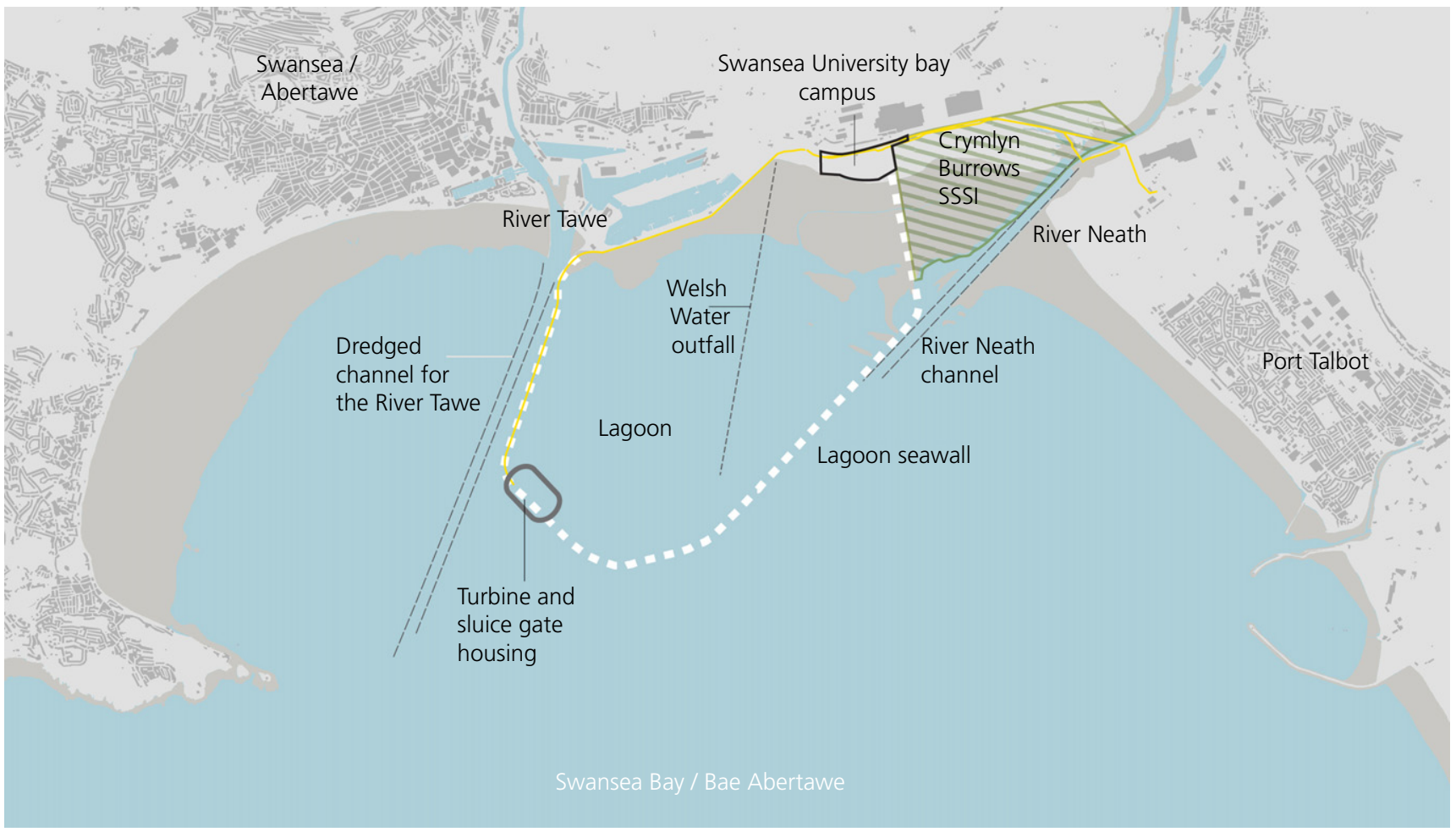

Figure 7. Illustration of the Swansea Bay tidal power lagoon (reproduced with permission of Tidal Lagoon (Swansea Bay) Ltd, LDA Design Consulting LLP and OS Open data) 
allow the Severn estuary to be developed by lagoons in a piecemeal way.

LongBay has proposed a Minehead lagoon along the coast of West Somerset. TLL has since proposed an enlarged Bridgwater Bay lagoon encompassing both the DECC Bridgwater Bay area and the Minehead lagoon. The installed capacity would be about $6 \mathrm{GW}$. Clearly, such a scheme would negate the LongBay scheme and would probably overlap with the main barrage scheme. PB has proposed a tidal lagoon on the Welsh coast west of Barry called Stepping Stones.

One problem with tidal energy from the Severn is that, even with ebb/flood generation, there would still be a period of about $3 \mathrm{~h}$ when generation would not take place. However, the tide on the North Wales coast is about $4 \mathrm{~h}$ out of phase with the Severn. Both TLL and North Wales Tidal Energy have announced plans to build a Colwyn Bay lagoon between Great Ormes Head and Prestatyn. This would enable tidal range power to be both predictable and continuous, although in varying amounts between spring and neap tides. Such competing schemes, while helpful in meeting the EU competition requirements, do not guarantee the best use of a finite longterm energy resource.

\section{Energy output}

The power and energy available from the tidal range schemes in the Severn estuary/Bristol Channel is shown in Table 1 (DECC, 2010a). However, the landfall of the HP barrage scheme is significantly further south. Thus, there would be some overlap of that scheme with the Bridgwater Bay lagoon.

From the table it can be seen that the energy output of the barrage is substantially greater than that from the lagoons. The smaller lagoons, such as the Swansea Bay, produce a small percentage of the energy output of the barrage. However, provided no lagoons are built within the main barrage line, a combination of the barrage and the downstream lagoons would produce about $7 \%$ of UK energy needs, a substantial renewable energy source.
The barrage would export its greater power to both ends of the barrage, that is, into the Welsh grid as well as into the English grid. Further, National Grid welcomed the opportunity to use the barrage as a new grid connection between Wales and England. Clearly, the greater power of the barrage would mean greater load on the national grid. During the DECC studies, National Grid estimated that appreciable grid reinforcement would be required, costing some $£ 2$ billion. However, the lower power output of an ebb/flood scheme would significantly reduce this requirement.

The optimism bias of $47 \%$ was added by the treasury to the capital cost based on the project risk and experience of other public sector projects. This resulted in DECC increasing the estimated cost of the main barrage scheme from $£ 23 \cdot 2$ to $£ 34 \cdot 3$ billion.

Using a social discount rate of $3 \cdot 5 \%$, the levelised cost of energy of the main barrage scheme was $£ 108 / \mathrm{MWh}$, with the Shoots (English Stones) scheme at $£ 121 / \mathrm{MWh}$ and Bridgwater Bay at $£ 126 / \mathrm{MWh}$ (DECC, 2010a). For comparison, the levelised cost of energy of the Swansea Bay lagoon is quoted as $\sim £ 150 /$ MWh (Poyry, 2014). The actual cost of private sector financing is higher, may be about $8 \%$; for projects with long construction periods, such as tidal range schemes, this would significantly increase interest payable during construction and would level out the cost. However, once the total construction cost is repaid, a high-cost scheme becomes a very low-cost scheme, as has happened at La Rance, now the cheapest electricity producer in France.

The government has agreed to offer developers a strike price under its contract for difference (CfD) scheme. For offshore wind, which can have several days with no output, this has reduced to about $£ 120 / \mathrm{MWh}$. Several companies have now abandoned offshore wind development in the Bristol Channel and elsewhere. The present government has put a cap on the total amount of money available under the CfD scheme. Due to the high capital cost of the barrage and large lagoons, these may need a larger sum than is currently available.

\begin{tabular}{lcccc}
\hline Scheme & Power: GW & Energy: TWh/year & Base cost: billion $f$ & With optimism bias: billion $f$ \\
\hline Cardiff-Weston DECC & 8.6 & $15 \cdot 6$ & $23 \cdot 2$ & $34 \cdot 3$ \\
Bridgwater Bay lagoon & 3.6 & $6 \cdot 2$ & $12 \cdot 0$ & $17 \cdot 7$ \\
Stepping Stones lagoon & 0.6 & $1 \cdot 2$ & $1 \cdot 7$ & 0.85 \\
Swansea Bay lagoon & 0.32 & 0.5 & $37 \cdot 75$
\end{tabular}

Table 1. Outputs and cost of the main energy schemes 
An offshore wind farm may have a life of only 30 years, whereas a tidal range scheme would have a life of about 120 years. Thus, once the capital cost had been written off, as at the La Rance tidal power scheme where the energy cost is the lowest in Europe, the long-term energy cost would be very low. Such benefit is not taken into account in the current government economic analysis that assumes a 40-year financial lifetime. It should be (ECCSC, 2013).

\section{Potential impacts}

\subsection{Basin water levels}

As shown in Section 2, the basin water levels would be changed appreciably. For the main barrage with ebb-only generation, the peak water level at high water springs Avonmouth would be reduced by about $2 \mathrm{~m}$ and the low water level would be raised by $\sim 6 \mathrm{~m}$ to around mid-tide level. For the ebb/flood generation schemes, the peak water level would be reduced somewhat more and the low water level would be midway between mid-tide and existing low tide levels, thus replicating the current tidal regime, being roughly symmetrical at about the mid-tide level. Such effects can be reduced by over-turbining, sluicing and operating the turbines as pumps.

A tidal barrage can also influence the tidal levels elsewhere. In the DECC studies, there was concern expressed that, for the main ebb generation scheme, far-field effects could occur in the north of Cardigan bay and off the southeast coast of Ireland for up to $250 \mathrm{~mm}$. However, this was based on a model boundary of Anglesey and southern Ireland. When the model boundary was extended to the continental shelf and ebb/flood generation tested by Professor Falconer, the far-field effects became very small and were effectively limited to the outer Bristol Channel (Falconer, 2013).

\subsection{Upstream ports}

For most lagoons, there is no upstream port traffic. However, for the main Severn barrage scheme, the ports upstream include Bristol (Portbury and Avonmouth), Cardiff, Newport and Sharpness. Bristol imports coal and imports/exports cars and other commodities, and in 2014, it was the 16th busiest port in UK. In the first half of 2013, about $5 \%$ of its shipping movements were vessels of over $13 \mathrm{~m}$ draught (Wood C\&J, personal communication). It has also received planning permission for an external deep sea container terminal (DSCT). However, due to the extra distance, European container ships would have had to travel up and back down the Bristol Channel and there had to be expansion of other UK container ports; therefore, the implementation of the DSCT is on hold for at least the next 5 years as there is insufficient container traffic to justify this scheme.

The increase in the low water levels would result in extended entry periods for the smaller sized ships. However, the lowering of the peak basin water levels would affect the ability of the larger ships to enter the ports. The DECC (2010b) studies proposed lowering the lock cills at Bristol, Sharpness and Newport to cope with this issue, although the project team did acknowledge later that this would interrupt ship movements during the significant construction period and that the provision of new adjacent and deeper locks would be a better solution. The ebb/flood scheme, which would lower the basin water level by rather more than the DECC ebb-only generation scheme, proposed similar action that would be paid for by the barrage company.

There is also the question of shipping traversing the barrage. For such schemes, large ship locks would be required. As it would be difficult to increase the size of such locks later, these would need to be built for the future and as planning consent has been obtained for the Bristol DSCT, these will need to be able to accommodate vessels in the ultra-large container class (366 m length, $49 \mathrm{~m}$ beam, $15.2 \mathrm{~m}$ draft) or greater. In addition, protection breakwaters would need to be constructed and any new navigation channels would need to be dredged. There would also arise the need to have smaller locks near the shore to take smaller recreational craft.

There is also loss of time for ships to traverse the barrage locks. This has been estimated to be about $45 \mathrm{~min}$ increase in transit time each way, without mitigation measures. While it is not possible to prevent this effect completely, improved logistics, coordination of transiting vessels and the increased duration of high tide levels should enable this impediment to be minimised (DECC, 2010b). In addition, some of the ships currently anchor downstream and wait for the tide. With raised water level upstream of the barrage, some of these would be able to transit the barrage when they would otherwise be moored, thus further reducing the barrage impact on shipping. However, this would entail a detailed study and negotiation with the ports and shippers who could be affected.

The lagoon schemes would not materially affect shipping except for the Bridgwater Bay lagoon which would affect the small amount of shipping entering the River Parrett.

\subsection{Flooding}

Along the sides of the Severn estuary, there are low-lying lands that are below sea level at times and are protected from flooding by sea defences. The Environment Agency (EA) is responsible for maintaining the appropriate levels of service for sea defence. Climate-change-induced sea level rise means that the defences will need to be raised, many by 2028 (DECC, 2010c). The lowered basin water level would mean that raising the sea defences could be postponed and this was calculated by DECC as having a net present value of $£ 219$ million (DECC, 2010c). Thus, the main barrage scheme would effectively 
provide flood protection to about 79000 residential properties, 10000 non-residential properties and benefit 42 essential infrastructure assets (DECC, 2010c).

In contrast, the lagoons would provide limited flood benefit.

Due to the raised low basin water level, it would be possible for the fluvial floods to not be able to discharge during low water levels resulting in tide locking and ponding. The DECC study found that for the main barrage line operating under ebb generation that resulted in low basin water not much lower than the mean tide level, pumping stations would need to be constructed. The present value of construction and operation was estimated to be $£ 124$ million (DECC, 2010c).

The ebb/flood barrage, with its lower low tide basin water level, would much reduce the tide locking effect and hence reduce to a great extend the construction and operation costs of overcoming it.

Climate change is expected to result in melting of the polar ice sheets and thermal expansion of the oceans. Estimates of sea level rise vary from about half a metre to about $3 \mathrm{~m}$ if the polar ice sheets melt. Whereas a lagoon would protect a limited amount of coast from such rises, the barrage would protect the area upstream. The barrage would also be of help when a tidal surge or tsunami occurred as it could be closed, thus protecting the coast from such damaging events.

\subsection{Recreation}

The current conditions in the Severn estuary, with its high tidal velocity and exposure to waves from the Atlantic, are harsh for recreational activities such as sailing, boating and swimming. For the barrage and lagoon schemes, the reduction in tidal velocities and the much shorter fetch would result in more benign current and wave conditions. This would greatly encourage sailing and other water sport.

\section{Environmental considerations}

\subsection{Sediment}

The high tidal velocities in the Severn result in the suspension of much sediment, resulting in turbid water. It is thought that there is about $30 \mathrm{Mt}$ in suspension during maximum spring tides, reducing to about $4 \mathrm{Mt}$ during neap tides (DECC, 2010d).

For the main barrage scheme, the peak suspended sediment concentrations are predicted to decrease by a factor of between 2 and 3 both within the impounded area and downstream. This is predicted to be associated with permanent deposition of up to $9 \cdot 4 \mathrm{Mt}$ of fine sediment. Much of this would be deposited within the deep channels and upstream of the old Severn Bridge.
Analysis showed that after 120 years of morphological response, involving erosion in some geographical areas and accretion in others, the range of final losses in the inter-tidal area is predicted to be similar to that with no scheme (DECC, 2010d). Lagoons can become sediment traps. For instance, the Bridgwater Bay lagoon was predicted to result in 43 million $\mathrm{m}^{3}$ of sediment accumulation. In addition to some loss of water volume, and hence power and energy, the sedimentation would have come from elsewhere, thus potentially reducing inter-tidal habitat elsewhere.

\subsection{Inter-tidal habitat}

Despite flood defence encroachment, there are large inter-tidal areas in the Severn estuary. Any tidal range power scheme will change the high and low water levels in the basin and hence lead to a reduction in inter-tidal habitat. The main ebb generation barrage without mitigation measures would lose about $160 \mathrm{~km}^{2}$ of habitat (DECC, 2010a). Mitigation measures can include topographic raising to raise the area that would no longer be uncovered at low basin water levels. This can be done by using necessary excavation along the line of the barrage and dredging of the navigation channels. This would reduce the inter-tidal loss to about $118 \mathrm{~km}^{2}$ (DECC, 2010a). It may also be possible to lower some of the areas that have become above high water level.

The ebb/flood generation barrage scheme, while losing more inter-tidal habitat to high water, loses much less below the mean tide level; thus the net loss is claimed to be $74 \mathrm{~km}^{2}$ (HP, 2013). Bridgwater Bay lagoon inter-tidal loss would be $26 \mathrm{~km}^{2}$; this could be reduced by mitigation measures to $16 \mathrm{~km}^{2}$ (DECC, 2010a).

\subsection{Compensation areas}

The Severn estuary is a special area of conservation (SAC) under the Habitats Directive (EC, 1992). This requires that compensation areas be provided on a like-for-like basis, as close as possible to the location of the negative effect to compensate for the areas lost. The area to be provided has to be larger than that lost by a margin to cover for the risk of it not replacing the full ecological performance of the land lost. For planning purposes, the DECC study used an area ratio of 2:1. For the Cardiff-Weston ebb generation barrage this would require some $240 \mathrm{~km}^{2}$, an unprecedented amount, involving a substantial and complex civil engineering project. The compensation areas would need to have achieved their new status by the time the original inter-tidal land is lost.

The Stepping Stones and Swansea Bay schemes would lose small amounts of inter-tidal habitat, but these are not within an SAC. 


\subsection{Water Framework Directive}

Article 4(7) of the Water Framework Directive (EC, 2000) requires that for a loss of habitat (DECC, 2010a)

all practical steps are to be taken to mitigate adverse effects

- the reasons are explained in the river basin management plans

a the reasons for the scheme are of overriding public interest

- the beneficial objectives cannot, for reasons of technical feasibility or disproportionate cost, be achieved by other means that are a significantly better environmental option.

\subsection{Birds}

The Severn estuary supports many species of water birds totalling about 70000 on average (DECC, 2010e). However, the Severn estuary has about the lowest density of water birds in the UK, probably due to the high tidal range, unstable bed, low biological productivity and harsh environment.

For the main barrage scheme, much of the inter-tidal habitat that would be lost is of a sandier and less stable substrate which thus supports less invertebrates and less birds (DECC, 2010e). With the tidal barrages, the reduced currents in the basin would result in reduced turbidity and a more stable bed. The increase in water clarity is expected to increase biological productivity and thus increase the densities of some invertebrate food sources available to water birds and so reduce the adverse effects of carrying capacity. As some of the lost inter-tidal areas are relatively unproductive as bird feeding habitat, very high compensation ratios should not be applied (DECC, 2010e). In mitigation, there would be the additional carrying capacity of the inter-tidal compensation areas following impoundment. All aspects would need careful study prior to implementation.

\subsection{Fish}

More than 100 fish species have been recorded within the Severn estuary. Internationally designated migratory species under the European Habitats Directive (EC, 1992) include salmon, shad, lamprey and eel. Three of the four rivers where shad spawn in the UK are within the basin of the main barrage scheme. The future baseline shows that, temperature increases with climate change, most of these species are at potential risk of stock reductions.

Fish can be affected by mortality/injury on passing through a turbine, noise disruption, disorientation leading to increased risk of predation and disruption to route of passage. The high tip speed of the bulb turbines would mean that turbine impact would be the biggest risk, although pressure change and shear can also have an effect on particular species. An extensive literature research was carried out for DECC, but with limited direct applicability. On the basis of certain assumptions, the models showed that there would be a potential risk of reduction in stock size, potential risk of river-specific extinction for sea trout and shad, and potential reduction in salmon and marine and freshwater species.

Measures to prevent and/or reduce fish impacts include fish ladders, fishways and noise guidance to fishways (Gibson \& Myers, 2002). The less dangerous part of the turbine is close to the hub where leading edge velocities are correspondingly lower than that at the tip. One potential is to use noise within the turbine to guide fish towards the hub (Turnpenny, 2013). Further, the greatest risk is when the turbines are operating at low flow when the water flow distance between sweeps may be lower. Previously, turbine rotation was synchronous with grid frequency. If inverters are used to allow the turbine rotational speed to be adjusted, then the risk of mortality would be lower. Further, for migratory fish, greater efforts could be made to improve water quality, access to natal rivers and specific spawning habitat, all of which are among the limiting factors for shad, salmon, river and sea lamprey and European eel at present. It should be possible to breed and stock fry, although recent research has resulted in Natural Resources Wales ceasing to stock rivers in Wales. Thus, there are a number of potential ways of reducing fish impact.

For the bulb turbines at La Rance, the blade tip speed is about $25 \mathrm{~m} / \mathrm{s}$. The VLH Rolls Royce turbine would have a tip speed of about $9 \mathrm{~m} / \mathrm{s}$. Tests at this tip speed show much reduced mortality. Tests introducing eels into a low-speed VLH turbine, about $4.5 \mathrm{~m}$ dia. and tip speed of $8 \mathrm{~m} / \mathrm{s}$, in France, showed no mortalities and very limited bruising.

The lagoon schemes do not have migratory rivers except for eels going up the Parrett at Bridgwater. However, there would be marine species and migratory stragglers entering the lagoons as a result of 'tidal swilling' (Turnpenny, 2013).

Clearly, more research and development is needed before one could be confident that the impact on fish would be at an acceptable level for lagoons, especially for any barrage.

\section{Tidal stream generation}

Another form of marine energy generation is by using tidal stream turbines. The turbines are like wind turbines but in the sea (Figure 8). These need to have large rotors to generate sufficient energy. These also need to have a clearance of about $5 \mathrm{~m}$ to avoid hitting small boats at low spring tide and a clearance from the sea bed of about 5-7 m, due to velocity sheer. Thus, the turbines need deep water, but need to be away from recognised navigation channels. The tidal stream needs to be generally above $2 \mathrm{~m} / \mathrm{s}$. All this limits the potential operational areas of tidal stream turbine arrays. 


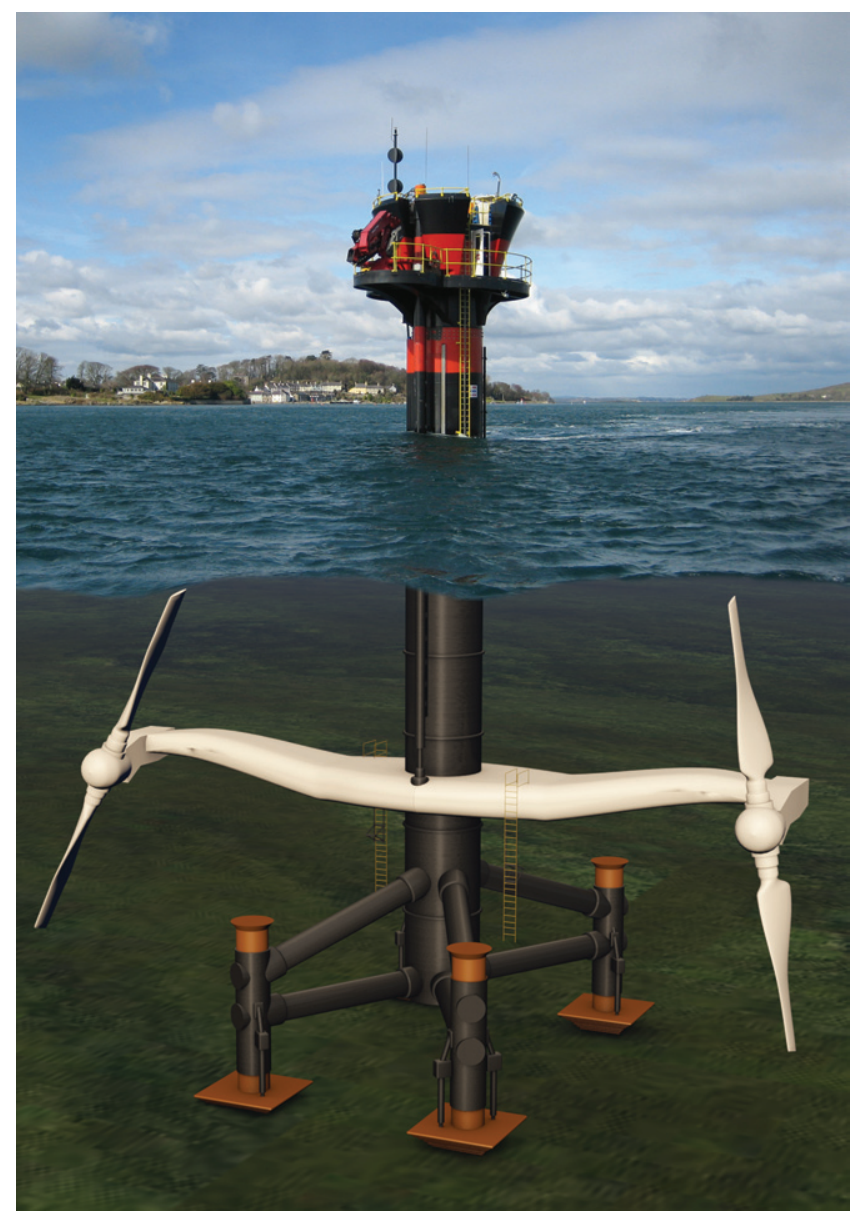

Figure 8. MCT Seagen Mark 2 tidal stream turbine (reproduced with permission of Marine Current Turbines Limited)

Marine Current Turbines (MCT) have been operating their 1.2 MW Seagen device at Strangford Lough in Northern Ireland since 2008. This has two $16 \mathrm{~m}$ dia. axial flow rotors. MCT are developing a $2 \mathrm{MW}$ turbine which would have $20 \mathrm{~m}$ dia. rotors. Both these require about $30 \mathrm{~m}$ of water depth. MCT are working towards two early commercial turbines in Kyle Rhea in Scotland and Anglesey. As yet, no commercial array has been installed although Atlantis hopes to install four turbines in the deep waters of Pentland Firth between northern Scotland and Orkney in late 2014. The feed-in tariff allowed by the government for this early commercial scheme will be $£ 305 / \mathrm{MWH}$, about six times the current wholesale price.

Figure 9 shows the existing peak tidal currents where the water depth exceeds $30 \mathrm{~m}$.

A minimum velocity of about $2 \mathrm{~m} / \mathrm{s}$ is needed for tidal stream. The plan below shows the area that meets these criteria. The Bristol Channel is used by many large ships going to the ports upstream, primarily Avonmouth and Portbury near Bristol; thus, any tidal stream array would need to avoid such shipping channels. Thus, much of the Bristol Channel would not be suitable for current generation of tidal stream turbines and the energy achievable would be very limited in comparison with tidal range schemes.

\section{Conclusions}

The Severn estuary and Bristol Channel, partly due to their combined shape, have the second highest tidal range in the world. The traditional tidal range energy scheme is an ebbgeneration barrage between Lavernock Point near Cardiff and Brean Down near Weston-super-Mare. This could provide about $15.6 \mathrm{TWh} /$ year, about $5 \%$ of the UK energy need. Recent studies have found ebb and flood generation beneficial as it followed the tidal curve closer, reduced the loss of intertidal habitat, reduced the peak power load on the grid and reduced the time period between power generations.

While this energy would be variable and intermittent, it would be predictable decades ahead. Tidal lagoons in the northwest would produce power about $4 \mathrm{~h}$ out of phase and would enable continuous power to be generated, although varying with spring and neap tides.

However, the barrage scheme would impede access to the upstream ports. The Severn estuary is an SAC. The scheme would need to meet the Habitats Directive criteria. Some of the fish are designated. However, passage through traditional bulb turbines is likely to result in fish mortality. HP proposed using low head and low fish impact contra-rotating turbines. These would need both turbine development and a detailed environmental study.

Several potential lagoon schemes have been proposed, two being within the barrage line. Lagoons would have minimal impact on shipping and a generally less environmental impact. Lagoons within the barrage line would remove storage volume from the barrage and render it less economical, and possibly unpromotable. Thus, lagoons within the barrage line would reduce the total potential energy output of the Severn. Thus, a policy decision needs to be made as to whether safeguard the barrage, and hence maximise potential energy from the Severn.

Tidal stream turbines have low energy output and are constrained by insufficient depth and velocity of water.

The optimum approach would appear to be to treat the Bristol Channel and Severn estuary as a holistic energy system, with a range of energy resources within each spatial area (Regen, 2012). 


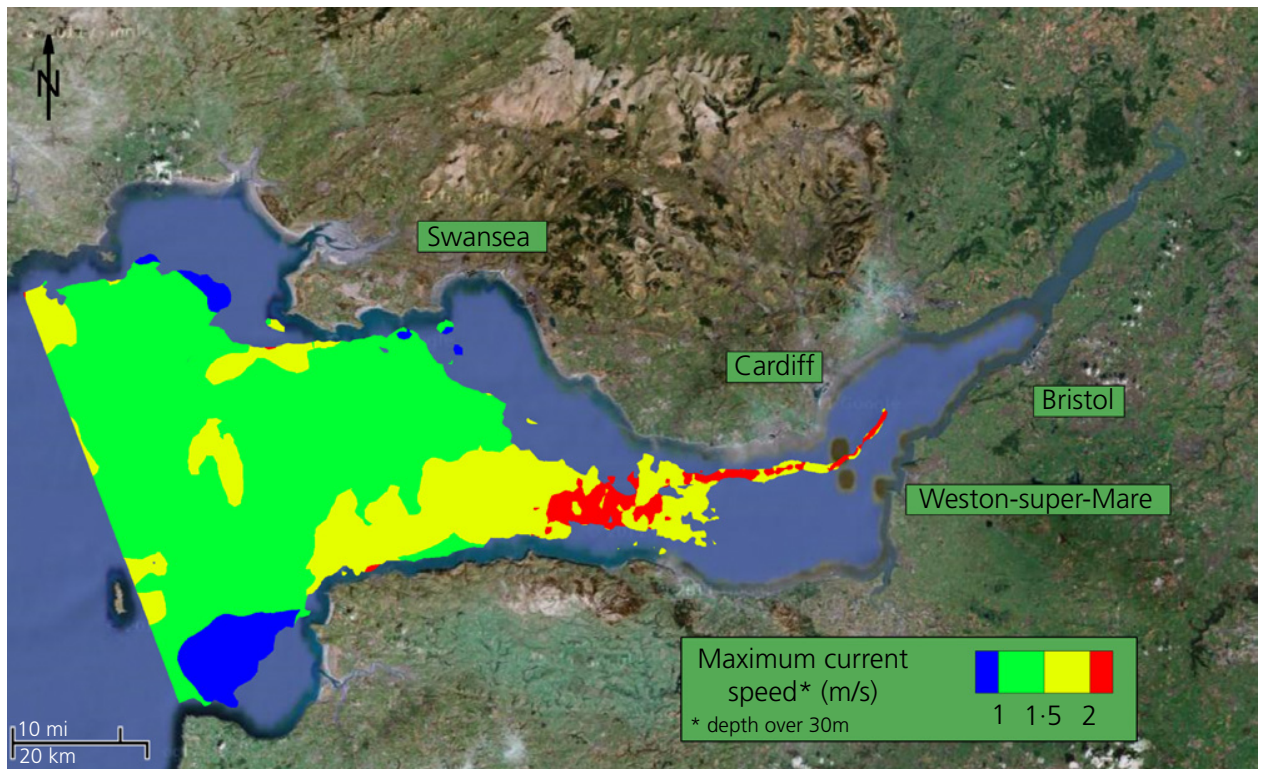

Figure 9. Existing peak tidal velocities (reproduced with permission of Professor Roger Falconer)

In summary, the Severn estuary and Bristol Channel could be a major source of tidal range renewable energy for the UK producing up to about $25 \mathrm{TWh} / \mathrm{year}$, providing for nearly $7 \%$ of UK's energy needs.

\section{Acknowledgements}

The authors acknowledge the support of Professor Roger Falconer, Cardiff University, Figures 1-3 and 9; EdF (http:// www.caravelles-et-ranceancefr/communities/6/000/001/340/706/ images/1620013.jpg figure 4); TSO, Energy Paper 57, The Severn Barrage Project 1989, Figure 2.4, Figure 5; DECC/ Parsons Brinckerhoff, Figure 6; Tidal Lagoon (Swansea Bay) Ltd., LDA Design Consulting Ltd. and OS Open data, Figure 7; Marine Current Turbines Limited, Figure 8.

\section{REFERENCES}

Atkins and Rolls Royce (2010) Concept Design of a Very-Low

Head Dual Generation Tidal Scheme for the Severn Estuary. Rolls-Royce, Derby and Atkins, Epsom, UK.

Baker GC (1992) Current status of tidal power in the Bay of Fundy. In Tidal Power: Trends and Developments (Clare R (ed.)). Thomas Telford, London, UK, pp. 15-22.

DECC (Department of Energy and Climate Change) (2010a) Severn Tidal Power: Feasibility Study Conclusions and Summary Report. Department of Energy and Climate Change, London, UK.
DECC (2010b) Severn Tidal Power - SEA Topic Paper: Navigation. Department of Energy and Climate Change, London, UK. DECC (2010c) Severn Tidal Power - SEA Topic Paper: Flood Risk and Land. Department of Energy and Climate Change, London, UK.

DECC (2010d) Severn Tidal Power - SEA Topic Paper: Hydraulics and Geomorphology. Department of Energy and Climate Change, London, UK.

DECC (2010e) Severn Tidal Power - SEA Topic Paper: Waterbirds. Department of Energy and Climate Change, London, UK.

Desroy N (2013) Tidal power and the aquatic environment of La Rance. Proceedings of the MAREN Conference, Galway, Ireland.

DoE (Department of Energy) (1981) Tidal Power from the Severn Estuary. HMSO, London, UK, Energy Paper 46.

EC (European Community) (1992) Council Directive 92/43/EEC of 21 May 1992 on the conservation of natural habitats and of wild fauna and flora. Official Journal of the European Communities L206/7.

EC (2000) Directive 2000/60/EC of the European Parliament and of the Council of 23 October 2000 establishing a framework for Community action in the field of water policy. Official Journal of the European Communities L327/1.

ECCSC (House of Commons Energy and Climate Change Committee) (2013) A Severn Barrage? Second Report 
of Session 2013-14, vol. 1. The Stationery Office, London, UK.

Falconer R (2013) Hydro-environmental impact. Studies for a Severn barrage. Proceedings of the Severn Barrage and Tidal Energy Conference, Cardiff, UK.

Gibson A and Myers R (2002) Effectiveness of a high-frequency fish diversion system at the Annapolis tidal hydroelectric generating station, Nova Scotia. North American Journal of Fisheries Management 22(3): 770-784.

HMSO (Her Majesty's Stationery Office) (1989) The Severn Barrage Project. General Report. STPG/CEGB/ Department of Energy, London, UK, Energy Paper 57. HP (Hafren Power) (2013) Severn Barrage Business Case. Hafren Power, London, UK, Energy Paper 57.

Kirby R and Retiere C (2009) Comparing environmental effects of Rance and Severn barrages. Proceedings of the Institution of Civil Engineers - Maritime Engineering 162(1): 11-26, http://dx.doi.org/10.1680/maen.2009.162.1.11.

Ko Y and Schubert DK (2011) South Korea's Plans for Tidal Power: When a 'Green' Solution Creates More Problems. Nautilus Institute, Berkeley, CA, USA.

PB (Parsons Brinckerhoff) (2008) Analysis of Options for Tidal Power Development in the Severn Estuary - Interim
Options. Parsons Brinckerhoff, London, UK, Analysis Report for DECC.

PB (2010) Options Definition Report. Parsons Brinckerhof, London, UK, on behalf of DECC.

Perier C (2013) The La Rance Tidal Power Plant Operation feedback after 40 years into service. Proceedings of the WATTS Wave and Tidal Technology Symposium, Cowes, UK.

Poyry (2014) Levelised Costs of Power from Tidal Lagoons - A Report to Tidal Lagoon Power plc. Poyry, Oxford, UK. Regen SW (2012) Bristol Channel Energy A Balanced Technology Approach Discussion Document. Regen SW, Exeter, UK, pp. 12-13.

STPG (Severn Tidal Power Group) (1986) Tidal Power from the Severn, Engineering and Economic Studies - The Cardiff Weston Scheme and English Stones Scheme. Severn Tidal Power Group, London, UK.

TLL (Tidal Lagoon Ltd) (2013) Tidal Lagoon (Swansea Bay) PLC Launches $£ 2$ Million Community Share Offer. Tidal Lagoon (Swansea Bay) PLC, Swansea, UK. Turnpenny A (2013) Challenges for fish migration. Proceedings of the ICE/RAE Severn Barrage and Tidal Energy Conference, Cardiff, UK.

\section{WHAT DO YOU THINK?}

To discuss this paper, please email up to 500 words to the editor at journals@ice.org.uk. Your contribution will be forwarded to the author(s) for a reply and, if considered appropriate by the editorial panel, will be published as discussion in a future issue of the journal.

Proceedings journals rely entirely on contributions sent in by civil engineering professionals, academics and students. Papers should be 2000-5000 words long (briefing papers should be 1000-2000 words long), with adequate illustrations and references. You can submit your paper online via www.icevirtuallibrary.com/content/journals, where you will also find detailed author guidelines. 